
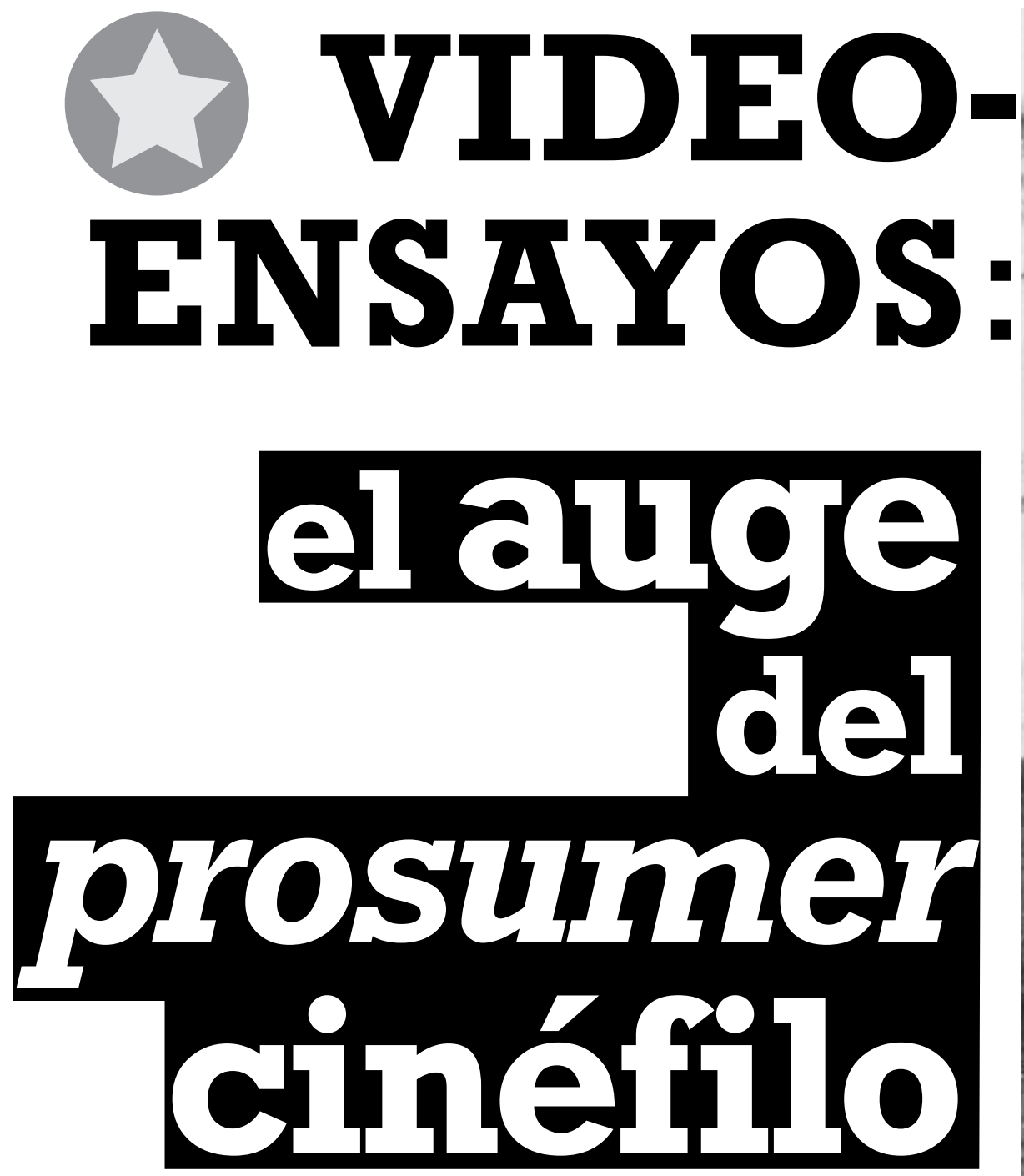

Ya sea en un aula de clases, un portal especializado como Fandor o un perfil de Facebook, la presencia de los

videoensayos en el mundo virtual es innegable. Cada vez más gente está

viendo películas, comentándolas, reeditándolas y subiendo su contenido

a internet, con lo cual fomenta el análisis y la discusión. ¿Qué significa eso para la crítica tradicional?

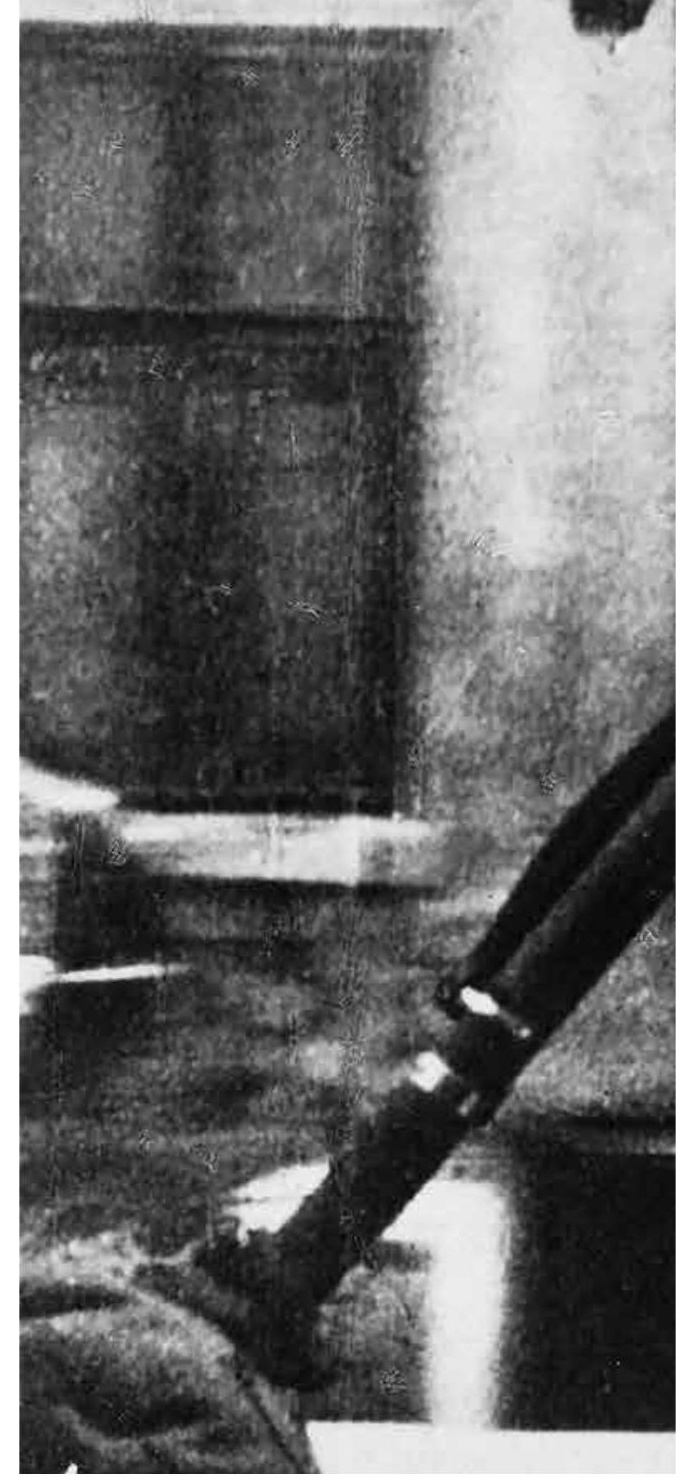


Un hombre con una cámara.4. Fuente: Pinterest

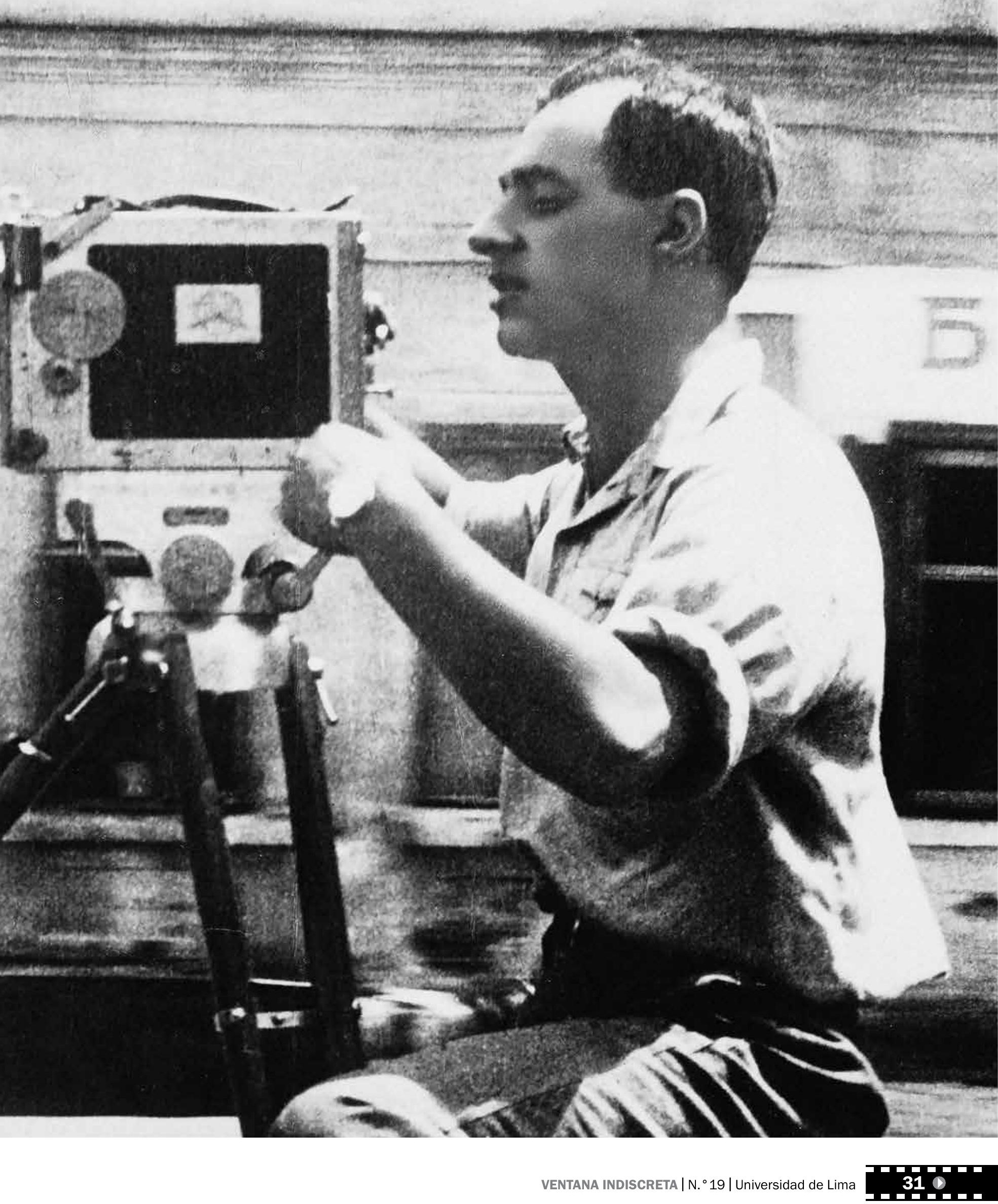


Cumplidas casi dos décadas del siglo XXI, los desarrollos de la tecnología de las comunicaciones resultan impresionantes. No solo la información viaja más rápido que nunca, sino que la cantidad de pantallas con las que lidiamos día a día, aun sin que las busquemos, resulta abrumadora. En el futuro todas las culturas serán culturas audiovisuales, lo cual quiere decir que las artes a las que les daremos mayor importancia también lo serán. No por nada el cine es producido hasta en los sitios más inhóspitos del mundo, y ya se habla de un "renacimiento" para la televisión y las series que la componen. A la par de esto tenemos al espectador, el consumidor de la imagen. Formado en esta cultura audiovisual, cada vez desde menor edad, se encuentra facultado para ver, criticar y hasta, en algunos casos, producir.

Internet ha permitido la consolidación de un nuevo formato que eventualmente recibió el nombre de videoensayo, un producto audiovisual de duración variable que hace uso de clips de otras películas, hipernarración y diferentes estilos de montaje para llevar a cabo un análisis, con frecuencia respecto a un film, una escena, un cineasta, etc., y constituye en sí mismo un elemento independiente del texto sobre el cual reflexiona. Una definición, por ahora provisional, que lo acerca al metatexto de Genette: un texto que comenta o discute otro que ya existe.

Aquí vamos a hablar únicamente de los ensayos audiovisuales cuyo tema principal de discusión es otro producto audiovisual, aunque reconocemos que en otras disciplinas (sociología, historia, arquitectura, etc.) el objeto de análisis no siempre será de naturaleza fílmica.

\section{Primeras bases}

Resulta dudoso sugerir un único antecedente. El cine autorreferencial, es decir, que se asume como tal para

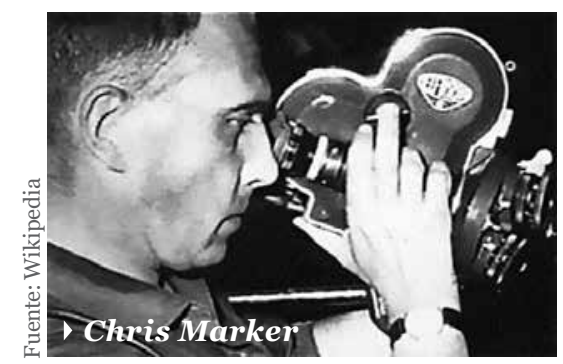

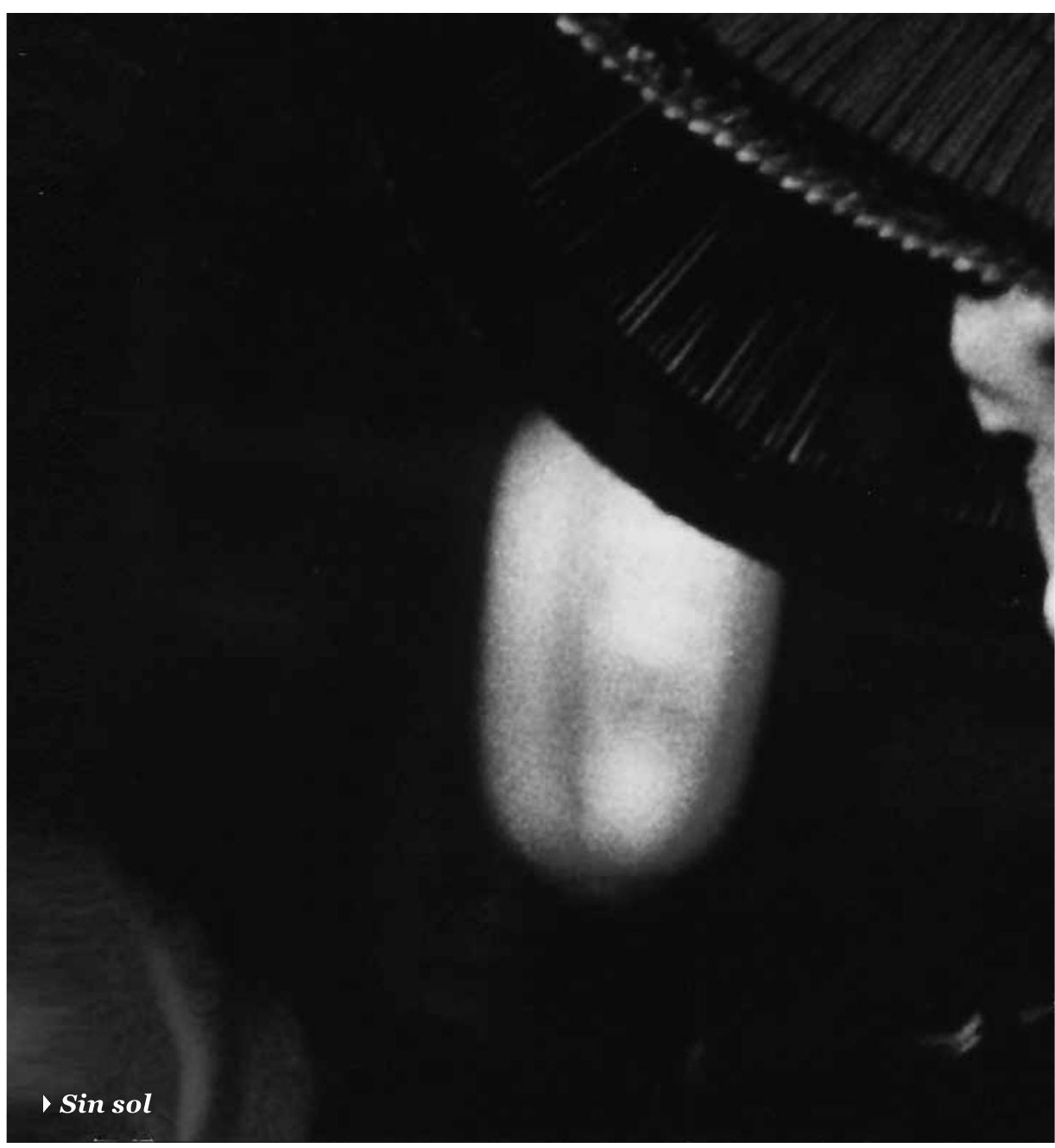

la audiencia, no es nuevo. Puede rastrearse hasta el trabajo de Vertov, sobre todo en Un hombre con una cámara (Chelovek s kino-apparatom, 1929). Hans Richter, cineasta y pintor, fue el primero en teorizar respecto a lo que llamó el "ensayo fílmico”, en 1940. Un ejemplo más próximo, no obstante, es el documental Sin sol (Sans Soleil, 1983), de Chris Marker, que le tomó varios años realizar antes de su estreno a principios de los ochenta. Marker editó fragmentos de otras películas y de programas de televisión, principalmente japoneses, grabando tomas adicionales con una cámara muda de $16 \mathrm{~mm}$. El resultado es una obra que se debate en la frontera del cine documental y los proyectos experimentales del videoarte.

Están presentes algunas características que luego heredaría el videoensayo en el siglo XXI: montaje de material ajeno, una tesis guiando el discurso, voz en off que sirve de precedente a la hipernarración. John Bresland (2010), profesor en el Departamento de Inglés de la Northwestern University, afirma que "Sin sol sigue siendo un sólido ensayo, un trabajo de no ficción que emana múltiples formas de cuestionamiento".

Sin embargo, las características formales no bastan para calificar el sus películas) como la única fuente de inspiración de lo que años después aparecería en la era de la internet. Se puede sugerir la metatextualidad, un rasgo más temático que figurativo, como elemento presente en todo videoensayo, mas no necesariamente exclusivo de él. Esto es: cine criticando cine. Del mismo modo que un crítico literario cita un verso para explayar mejor su análisis, el videoensayista incorpora al montaje la escena a la cual ha de referirse. El fin es el mismo, el concepto también, pero el material de trabajo cambia. trabajo de Marker (esta y otras de 

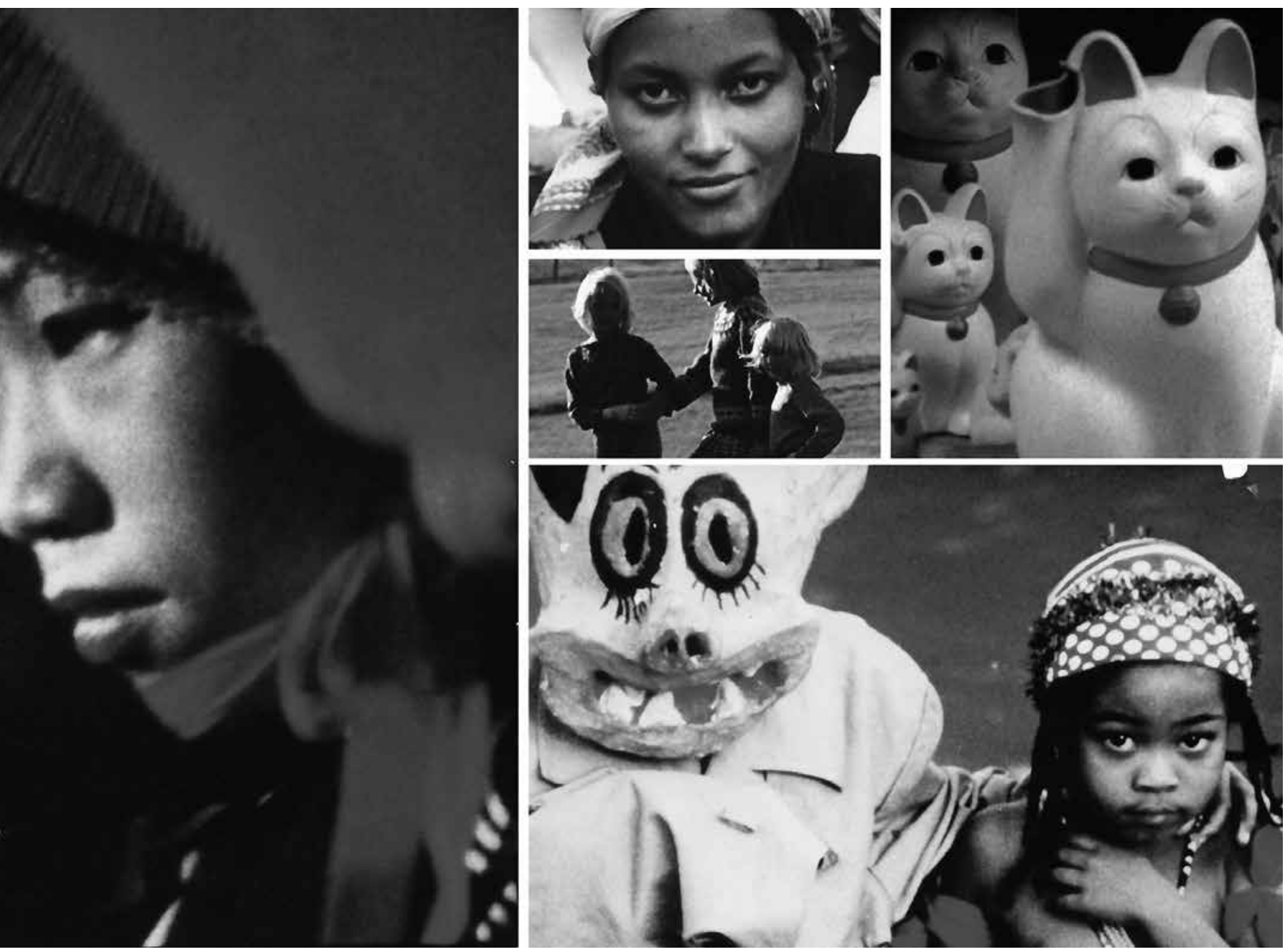

En Historias de cine (Histoire(s) du cinéma, 1988-1998), Jean-Luc Godard narra una serie de argumentaciones respecto a las diversas formas en las que puede concebirse una historia del cine, cuajada en múltiples subhistorias. Se apoya, de vez en cuando, en citas de autores como Emily Dickinson. Experimenta con diversas formas de montaje, y genera secuencias que recuerdan a Vertov.

Igual que en la filmografía de Marker, el proyecto comparte algunos rasgos que luego el videoensayo habría de rescatar, pero siguen existiendo diferencias, formales $\mathrm{y}$ temáticas. Primero, la tesis de Godard no resulta del todo clara, mucho menos se manifiesta a lo largo de su intrincado discurso. Por lo mismo, es difícil clasificar los argumentos o siquiera afirmar que existen. Frases declarativas como "el cine no forma parte de la industria de las comunicaciones ni del espectáculo, sino de la de los cosméticos, sucursal del de la mentira" son escasas. Se encuentran esporádicamente en medio del caos del montaje. En otras palabras, el discurso de Godard es difuso, o muy poético o demasiado sentencioso. Los puntos medios, frecuentes en la retórica ensayística, son muy pocos.

\section{Ordenando formas}

Comparemos el ejercicio de Godard con, por ejemplo, Moving Pictures: Visual References and Artistry in the Works of David Lynch (2016), videoensayo de Andreas Halskov. En diez minutos, Halskov analiza los encuadres de varias películas de la filmografía de Lynch, y argumenta que, a diferencia de empezar con una historia, el director surrealista opta por una imagen, que a su vez hace referencia a una obra de otro artista, que puede ser René Magritte, Francis Bacon o Salvador Dalí. Halskov presenta claramente una tesis al inicio del video, y la acompaña de tres argumentos que la complementan y que son desarrollados luego sobre la base de evidencia consistente.

Las diferencias con el trabajo de Godard son obvias: la duración es menor, la argumentación es clara, el discurso de la hipernarración encaja como un rompecabezas; podría transcribirse y no habría el menor problema. El montaje es mucho más convencional (se prima el corte directo), el autor opta por un aspecto de un único director y respeta esos límites. El universalismo de Historias de cine está ausente.

De manera similar, en el ensayo Camera Movement in Narrative Cinema (2015), Jakob Isak Nielsen propone un punto de vista respecto a las funciones que desempeñan los movimientos de cámara como un elemento constitutivo del lenguaje audiovisual. Luego pasa a enumerar- 
los y desarrollarlos con ejemplos. A diferencia de Halskov, en este caso se trata de un aspecto más universal para las reglas de producción cinematográfica (los movimientos de cámara), pero la estructura central sigue siendo la misma: una introducción al tema, una tesis, su desarrollo $\mathrm{y}$, finalmente, una conclusión.

Hemos dado con una palabra fundamental para el videoensayo: estructura, que nos remite a nociones de coherencia, un sistema, un orden, una secuencia lógica, destinada a terminar desde el momento mismo que inicia. Puede entenderse, en realidad, como un requisito para dicha nomenclatura. Empezando con Montaigne en el siglo XVI, el ensayo ha sido configurado como género literario en gran medida por el mundo académico, y ha establecido una normatividad estricta sobre sus principales aspectos formales y una tendencia intelectual claramente cientificista. Sería más preciso hablar de lo ensayístico en tanto característica fundamental de un discurso, el cual puede manifestarse de muchas formas y a través de muchos lenguajes.
El soporte físico no es lo que vincula los trabajos de Montaigne con los de Halskov y Nielsen (así como muchos otros ensayistas). Lo que comparten es una toma de posición fruto de la subjetividad del autor, un rasgo que precede a cualquier tipo de producción literaria, ya sea audiovisual o escrita. Bresland (2010), siendo él mismo un ensayista, es particularmente claro con respecto a este punto.

En cuanto a su intención, el videoensayo no difiere de su contraparte escrito, el cual por miles de años ha sido un medio para que los escritores confronten preguntas difíciles de responder por escrito. El ensayista se impulsa hacia algún descubrimiento o verdad. El mismo suele ser difícil de conseguir, en tanto el ensayo por lo general pregunta más de lo que responde.

Por lo mismo que los autores trabajan desde un punto de vista particular, se hallan sujetos a la refutación (propia y ajena). El ensayo es susceptible a la corrección, a la crítica, a la dialéctica. Tiene una habilidad excepcional para suscitar

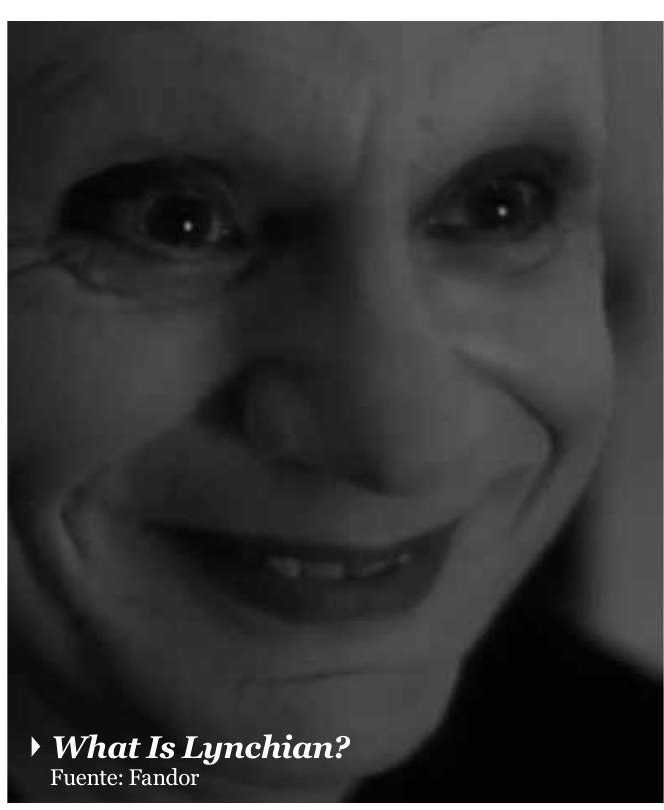

controversia, justamente por la subjetividad que implica. Concluimos que este tipo de texto no puede dar con absolutos, por más que lo intente. No logra acallar a otros locutores sino provocarlos, los incita a que hablen, a que la discusión no termine nunca, que siempre se pueda ir un

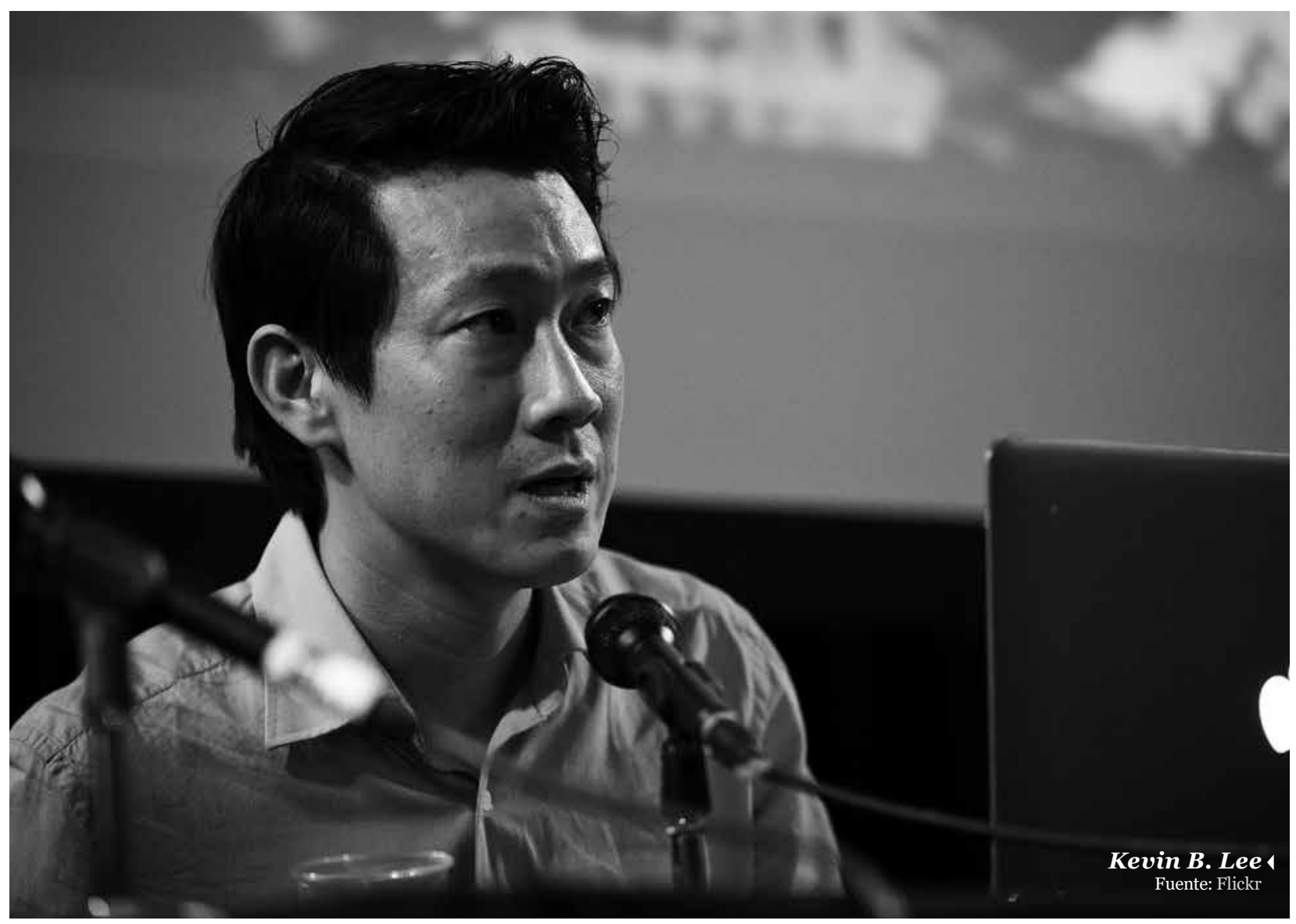



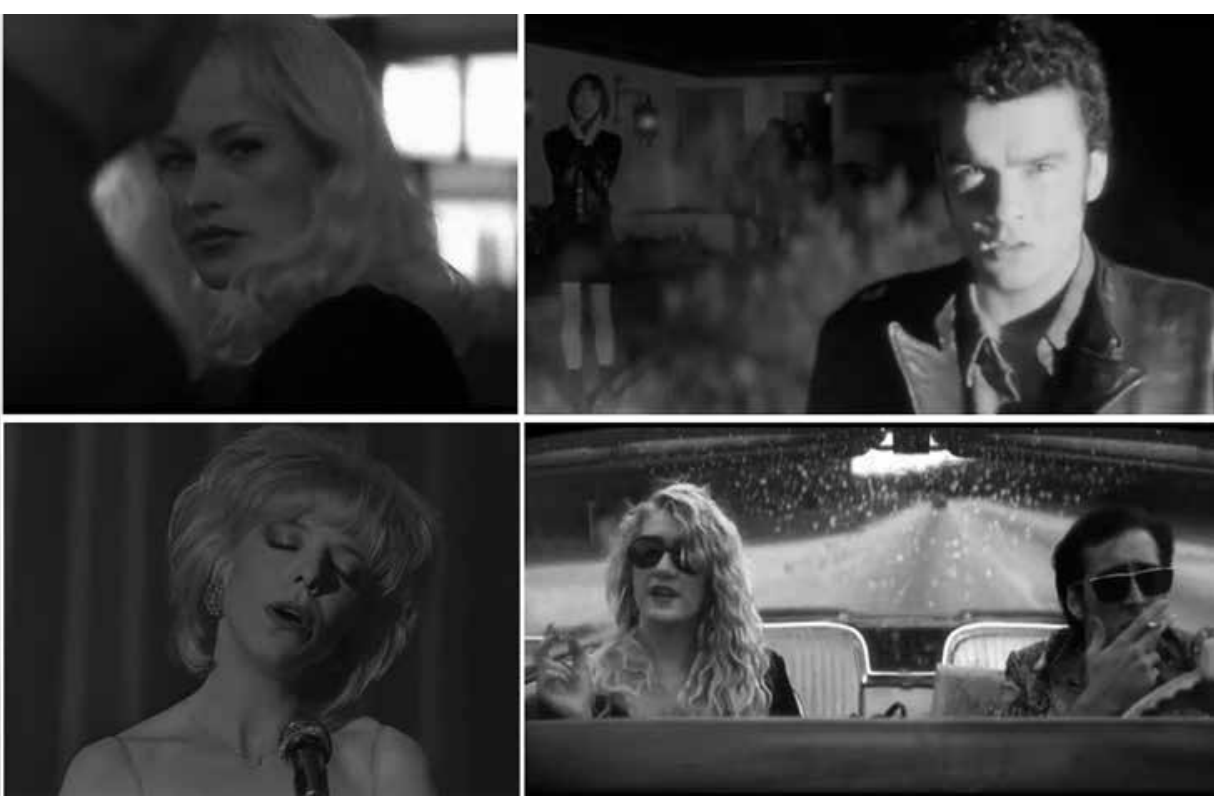

paso más allá. Los ensayos (escritos o audiovisuales) pueden empezar o prolongar un debate, pero nunca terminarlo.

Según Kodwo Eshun (2014), profesor en el Departamento de Culturas Visuales de la Universidad de Londres, esto tiene que ver con en la noción fundamental de lo que debe ser un ensayo:

Para mí, lo ensayístico no tiene que ver con una particular y genérica fascinación por la voz en off o el montaje. Lo ensayístico es disatisfacción, es descontento con los deberes de una imagen y las obligaciones de un sonido.

El descontento del que habla Eshun es el verdadero rasgo fundamental para que algo pueda ser llamado un ensayo. Es un atributo ajeno a la extensión, a los términos especializados, a las frases bien citadas. Es la puesta en práctica de ideas, concordancias y disonancias de un autor. El producto acabado es un ensayo desde el momento de su concepción.

\section{Lo estándar, lo formal}

Quizá un docente o un investigador de lo audiovisual podría buscar "videoensayos" en internet, ver una o dos propuestas y rápidamente decir que, a su juicio, esos no son ensayos.
No al menos en el aspecto formal del término. Pensemos por ejemplo en lo que el portal web Fandor nos llegó a ofrecer. Fundado en el 2010, el sitio web ha servido de portal para un número impresionante de videoensayos, en su mayoría producidos bajo la supervisión de Kevin B. Lee hasta el año 2016, tal vez el más reconocido videoensayista en internet. Desde

\section{La flexibilidad de los} videoensayos como formato libre es lo que permite esta variedad de formas de narrar, aunque cualquier teoría que se pretenda establecer sobre la base de ellos debe ser planteada con precaución.

el 2007, ha producido más de 300 de estos videos (gran parte de ellos para Fandor) en los que analiza escenas, directores, técnicas, estilos, vanguardias, etc., y tiene en su haber un título de bachiller por la School of the Art Institute of Chicago.

En uno de ellos, llamado What Is Lynchian? (2015), Lee presenta varias tomas de las películas de David Lynch en busca de los elementos (visuales, sonoros y temáticos) que componen su particular estilo cinematográfico. El título del video anuncia ya el desconocimiento de Lee sobre el tema: su discurso es muy amplio (incluso vago), sigue una dirección fija pero flexible y parte de la pregunta inicial del título. El trabajo de la voz en off depende estrictamente de contar con las imágenes correctas en el momento correcto, por lo que transcribirlo tal cual sería un problema. Está en un plano diametralmente opuesto al ensayo de Halskov, cuya hipernarración calza perfectamente ya en video o en papel. Lo único que ambos autores tienen en común es su fascinación por el director surrealista.

El trabajo de personas como Halskov, Nielsen, Adrian Martin, Cristina Álvarez o Thomas van den Berg es muy diferente, más sujeto a la convención literaria. El mismo Lee, tras analizar lo que ellos consideraban un ensayo cinematográfico, dijo no estar seguro de si lo que él hacía calificaba como "ensayístico". Casi ninguno de sus videos supera los ocho minutos de duración y están llenos de diferentes técnicas de edición, hipernarración y efectos, las cuales los hacen visualmente muy atractivos. Por su parte, (Un)Reliable (Un)Reliability de Van den Berg tiene una terminología especializada, citas, definiciones, muchos momentos de silencio, prima con creces el corte directo, dura considerablemente más y, quizá la mayor diferencia, está concebido como material de clase (si acaso no es ya una clase en sí mismo). Viendo lo diferentes que son estos trabajos, las dudas de Lee son comprensibles, pero ello no desacredita su trabajo, ni el de otros realizadores análogos como Matt Zoller, Kogonada, Adam Cook, Jacob Swinney, Sander Spies, Tony Zhou o Nelson Carvajal.

Nos encontramos, al parecer, ante dos tendencias dentro del formato del videoensayo. Por un lado, los que cuentan con una estructura clara, una tesis, argumentos, una conclusión, usualmente hechos por perso- 
nas con estudios y experiencia en la docencia. Con frecuencia, si no siempre, creados con fines educativos y ciñéndose a las reglas de la academia, lo que complica su circulación en internet sin arriesgarse a infringir las normas de derechos de autor. Por otro lado, están aquellos que no presentan siempre una estructura única, su discurso es una reflexión fluida (más difícil de separar por argumentos), emplean múltiples formas de edición y se encuentran en páginas como Fandor, IndieWire, No Film School, etc. Los realizadores de estos videos no se dedican a la docencia, sus proyectos no se producen con miras a ser vistos en un salón de clase sino en privado, desde una laptop o la pantalla de un celular.

En ambos casos, el lenguaje audiovisual es de suma importancia, así como lo son el ritmo, la hipernarración, la selección de las imágenes y, sobre todo, el montaje. Conor Bateman, videoensayista que ha publicado en Fandor, reconoce una gama amplia de recursos visuales que los editores tienen a su disposición. Entre los más populares está el supercut, que consiste en editar varias tomas sobre la base de una categoría o un tema, prescindir casi en su totalidad de texto o hipernarración y generar un producto en donde la retórica es ciento por ciento visual (The Doorway Shot de Jacob Swinney). En ocasiones se sigue un análisis más estructurado, enfocado en la cualidad connotativa del film para dar con un subtexto o una temática oculta (Birdman's shifting spaces de Joost Broeren y Sander Spies).

Otra técnica frecuente es la comparación o split screen, en donde la pantalla se divide en varias secciones, para contrastar escenas según un criterio puntual (las series Seeing Double y Seeing Triple de Davide Rapp). Cabe mencionar que la división de la pantalla fue algo con lo que Vertov experimentó en su momento, hace casi un siglo. Se encuentran también intentos de deconstrucción, análisis a profundidad de una escena o secuencia, para tratar de entender cómo un plano, la luz o el tipo de lente aporta al producto final. Decisions, decisions, de Adrian Martin y Cristina Álvarez, es una mezcla interesante de estos dos últimos formatos, pues contrasta escenas de El audaz (The Hustler, 1961) de Robert Rossen y Magia a la luz de la luna (Magic in the Moonlight, 2014) de Woody Allen, a la vez que descompone sus rasgos más elementales, los compara y da un veredicto.

La flexibilidad de los videoensayos como formato libre es lo que permite esta variedad de formas de narrar, aunque cualquier teoría que se pretenda establecer sobre la base de ellos debe ser planteada con precaución. Como casi todo en internet (que por ahora es su principal soporte), es un fenómeno sumamente variable. La clasificación que hemos propuesto más arriba puede ser obsoleta en un par de años.

\section{Necesidad de contar}

Los videoensayos han dotado a una cantidad abrumadora de cibernautas del medio para volverse ellos mismos los críticos. El nacimiento del formato se ubica a la sombra de la democratización global que supone la llegada de internet, el desarrollo del diseño de software y el soporte digital. Al mismo tiempo, el formato cobra fuerza en el mundo académico (como hemos visto) al adoptar una serie de estándares y parámetros más estrictos, sobre todo en lo que respecta al copyright, que los docentes están en su derecho de mantener. Uno de ellos es Tag Gallagher, quien además se ha desempeñado como historiador y crítico de cine.

Desde la década de los noventa, Gallagher procura utilizar los últimos avances tecnológicos al momento de dictar su cátedra, pero la aparición de los ensayos audiovisuales (algunos producidos por él) han hecho posible lo que en otra época era una tarea sumamente compleja. Elpidio del Campo (2012), docente en la Universidad Miguel Hernández de Elche, le dedicó un artículo al trabajo de Gallagher, en el cual recoge la siguiente cita:

Cuando daba clases siempre era un problema mostrar fragmentos de una película, porque solamente se disponía de una copia de 16 mm [...] Algunos profesores juntaban a los alumnos alrededor de una pequeña máquina de moviola; pero, básicamente, era casi imposible estudiar incluso un fotograma en una clase, por no hablar de las relaciones entre los planos, o de movimiento, etc. (p. 1337).
En palabras de Del Campo, desde mediados de los años ochenta se fueron popularizando cintas y reproductores de videocasete. Fue esto lo que les permitió a docentes como Gallagher mejorar enormemente las lecciones que dictaban en sus respectivas instituciones. Mejoría que en su momento fue impulsada por la urgencia de contar con material de apoyo que fuese didáctico y fácil de conseguir.

Pero los videoensayos no tienen que restringirse a un salón de clase. Han trascendido su condición de material pedagógico, y han dado cuenta de un nuevo tipo de espectador-productor, un prosumer cinéfilo, figura que desmiente la pasividad con la que algunos directores aún imaginan a su audiencia. La alfabetización contemporánea es tanto escrita como audiovisual, lo cual implica no solo saber leer una imagen en movimiento sino producirla. Quizá volverse un crítico profesional no sea la meta de la mayoría de los editores de videoensayos, pero muchos de ellos estarían más que facultados para esa labor. Los campos de la producción y la crítica audiovisual (ahora convergentes) se encuentran abiertos, quizá como nunca antes. 


\section{> Tag Gallagher}

Fuente: Flickr

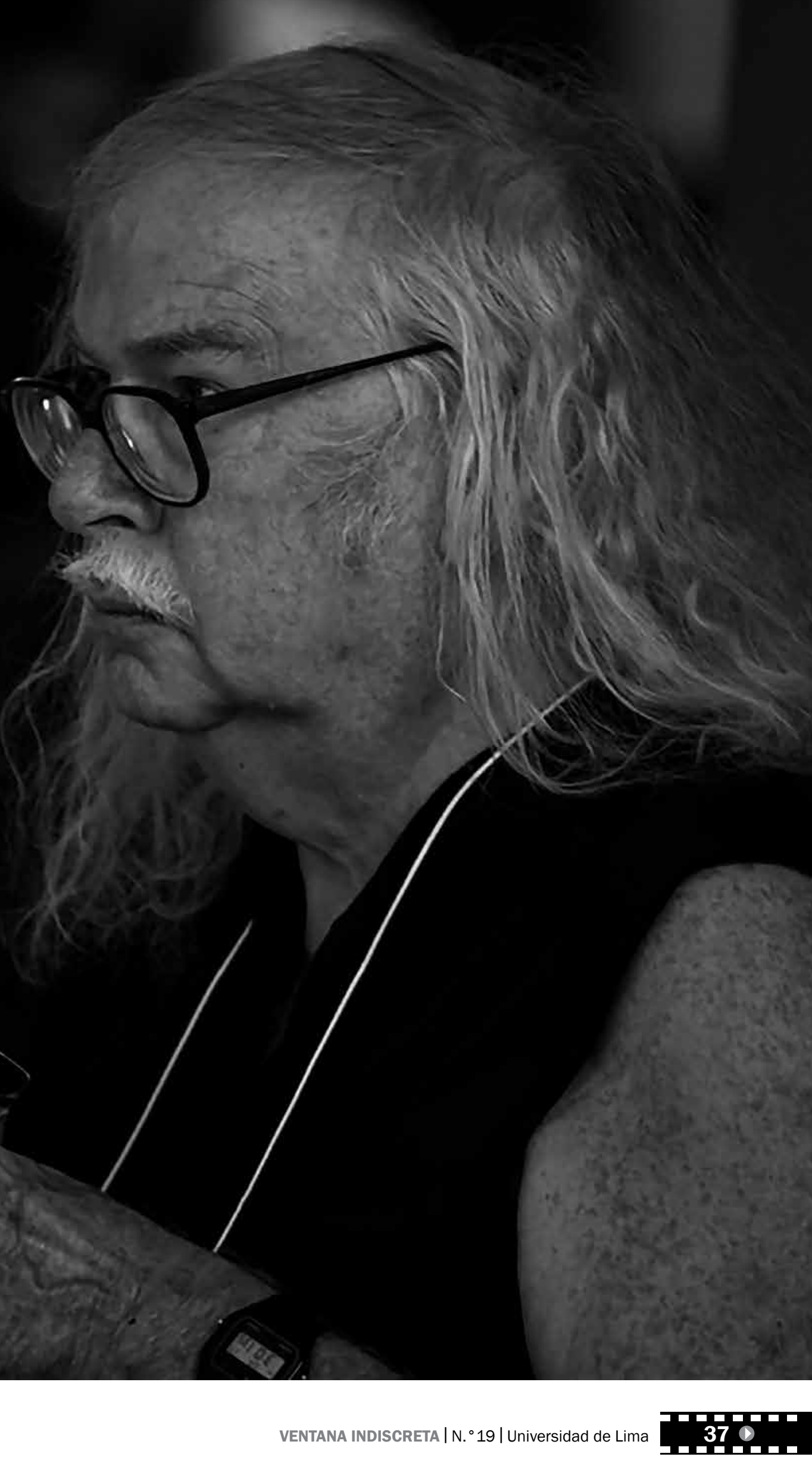

